\title{
Zinc Stearate Production by Precipitation and Fusion Processes
}

\author{
Mehmet Gönen, Devrim Balköse,* Fikret İnal, and Semra Ülkü \\ Department of Chemical Engineering, İzmir Institute of Technology, Gülbahce Koyü-Urla, \\ 35430 Izmir, Turkey
}

\begin{abstract}
In this study, the production of $\mathrm{ZnSt}_{2}$ using sodium stearate and zinc sulfate in a precipitation process, and stearic acid and zinc oxide in a fusion process, was investigated with regard to product purity. In the fusion process, an increase in mixing rate decreased the induction time occurring at the beginning of the reaction. While the melting point of the zinc stearate prepared by the precipitation process was found to be about $122^{\circ} \mathrm{C}$ by optical microscopy, it was slightly lower than $122{ }^{\circ} \mathrm{C}$ for zinc stearate produced by the fusion process. Differential scanning calorimetry (DSC) indicated onset of melting at $120^{\circ} \mathrm{C}$ and $118{ }^{\circ} \mathrm{C}$ for samples prepared by precipitation and fusion processes, respectively. Characteristic peaks of $\mathrm{ZnSt}_{2}$ were present in XRD patterns of the products obtained by both processes. From SEM micrographs, it was seen that zinc stearate obtained by both processes had lamellar structure.
\end{abstract}

\section{Introduction}

The long-chain carboxylates of metal ions are compounds of considerable commercial importance and find applications in areas such as driers in paints or inks, components of lubricating greases, heat stabilizers for plastics (especially PVC), catalysts, waterproofing agents, fuel additives, and cosmetic products, etc. ${ }^{1}$ Zinc stearate $\left(\mathrm{ZnSt}_{2}\right)$ is one of the important ionic surfactants of metal soaps. In addition to the aforementioned applications, $\mathrm{ZnSt}_{2}$ has been recently used in preparation of Langmuir-Blodgett (LB) mono- and multilayers. ${ }^{2}$ Metal soaps are manufactured by using one of the following three processes: double decomposition (precipitation process, eq 1), direct reaction of carboxylic acid with metal oxides, hydroxides, and carbonates (fusion proces, eq 2), and direct reaction of metals with molten fatty acids (eq 3). Considering some of the metals give no reaction with organic acids, and the absence of pure metals in nature, the first two processes are generally preferred for pure product manufacturing. ${ }^{1}$

$$
\begin{aligned}
& \begin{array}{l}
2 \mathrm{C}_{17} \mathrm{H}_{35} \mathrm{COONa}_{(\mathrm{aq})}+\mathrm{ZnSO}_{4} \cdot 7 \mathrm{H}_{2} \mathrm{O}_{(\mathrm{aq})} \\
\left(\mathrm{C}_{17} \mathrm{H}_{35} \mathrm{COO}\right)_{2} \mathrm{Zn}_{(\mathrm{s})}+\mathrm{Na}_{2} \mathrm{SO}_{4(\mathrm{aq})}+7 \mathrm{H}_{2} \mathrm{O}_{(\mathrm{l})}
\end{array} \\
& \mathrm{ZnO}_{(\mathrm{s})}+2 \mathrm{C}_{17} \mathrm{H}_{35} \mathrm{COOH}_{(\mathrm{l})} \rightarrow \\
& \left(\mathrm{C}_{17} \mathrm{H}_{35} \mathrm{COO}\right)_{2} \mathrm{Zn}_{(\mathrm{l})}+\mathrm{H}_{2} \mathrm{O}_{(\mathrm{g})}(2) \\
& \mathrm{Zn}_{(\mathrm{s})}+2 \mathrm{C}_{17} \mathrm{H}_{35} \mathrm{COOH}_{(\mathrm{l})} \rightarrow\left(\mathrm{C}_{17} \mathrm{H}_{35} \mathrm{COO}\right)_{2} \mathrm{Zn}_{(\mathrm{l})}+\mathrm{H}_{2(\mathrm{~g})}
\end{aligned}
$$

The precipitation process generally produces metallic soap by the reaction of an aqueous solution of a watersoluble metal salt and a fatty acid alkali metal salt at a temperature below the boiling point of water under atmospheric pressure. Filtering, washing, and drying are the important steps in this method. Manufacturing of metal soaps using the precipitation process has been studied extensively. ${ }^{3,4}$ Double decomposition reactions

* To whom correspondence should be addressed. Tel.: +(90)232-7506271. Fax: +(90)232-7506196. E-mail: devrimbalkose@iyte.edu.tr. of crude oleic soaps and inorganic compounds indicated cation exchange reactions were temperature dependent and that the presence of ethanol in the reaction medium enhanced the rate of reaction. ${ }^{5}$ The fusion process, however, produces metal soaps by the reaction of metal oxides, hydroxide, carbonate, or acetate with a molten fatty acid at temperatures sufficiently high to form metal soaps. Instead of washing and drying processes, a grinding step becomes important to obtain a product with desired particle size. The fusion process also has been examined. ${ }^{6-8}$ One of the important parameters encountered in the fusion process was long reaction time - up to 3-4 h. This problem was overcome by using either azelaic acid, phthalic acid, citric acid, or succinic acid as catalysts in the fusion process. ${ }^{8}$

Physicochemical properties of metal soaps are determined by the nature of the metal ion and organic acid. Unlike the conventional carboxylates of $\mathrm{Na}$ and $\mathrm{K}$, they are generally water insoluble or sparingly soluble. There are various studies on different metal soaps in the literature. The structure and thermal behavior of some long-chain cerium (III) carboxylates were also studied. ${ }^{9}$ It has been shown that the solid phase has a lamellar, bilayer structure with planes of the cerium(III) ions coordinated to the carboxylate groups. Melting points of certain soaps have been reported differently because of impurities in the product. ${ }^{1}$ Synthesis and characterization of iron stearate compounds was reported by Abrahamson and Lukaski. ${ }^{10}$ The structure and transition behavior of $\mathrm{ZnSt}_{2}$ by infrared and XAFS spectroscopies were investigated by Ishioka et al. ${ }^{11}$ From XAFS analysis, the coordination number of the carboxylate group around the zinc atom was evaluated as 4 and the $\mathrm{Zn}-\mathrm{O}$ distance was $1.95 \AA$.

There are a number of studies regarding the use of zinc stearate as a heat stabilizer for poly(vinyl chloride) (PVC). While it was expected to obtain very good thermal stabilization of PVC, the use of commercial $\mathrm{ZnSt}_{2}$ with its costabilizer, aluminum stearate, in PVC stabilization induced PVC degradation due to either insufficient mixing of PVC and stabilizers or presence of impurities in stabilizers. ${ }^{12}$ Thus, preparation of pure $\mathrm{ZnSt}_{2}$ is important for PVC thermal stabilization applications. 


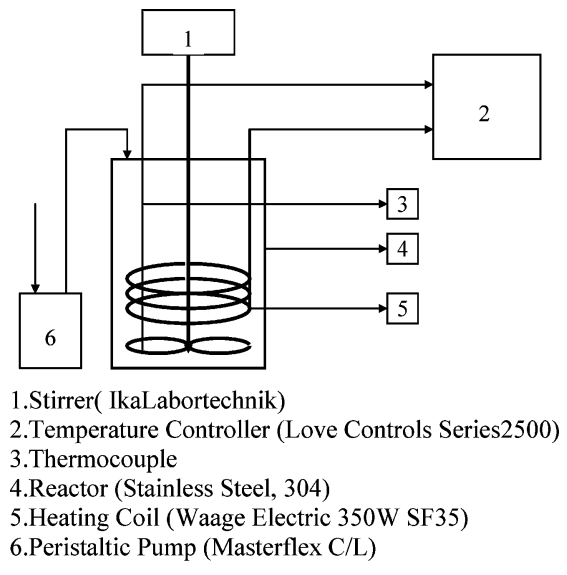

Figure 1. Experimental setup.

Investigation of effects of production technique (namely precipitation and fusion), by using a well-characterized stearic acid used in soap in industry, on product properties and on purity of $\mathrm{ZnSt}_{2}$ were the aim of this study.

\section{Experimental Section}

$\mathrm{ZnSO}_{4} \cdot 7 \mathrm{H}_{2} \mathrm{O}$ and $\mathrm{ZnO}$ (99\%, Merck), technical grade stearic acid (octodecanoic acid), and $\mathrm{C}_{17} \mathrm{H}_{35} \mathrm{COOH}$ (commercial product, Dalan Soap Factory, Turkey) were used in the experiments. The acid value of the stearic acid was $208.2 \mathrm{mg} \mathrm{KOH} / \mathrm{g}$ of stearic acid and it consisted of $47.7 \%$ palmitic acid (hexadeconaic acid) with $\mathrm{C}_{16}$ alkyl chains and $52.3 \%$ stearic acid with $\mathrm{C}_{18}$ alkyl chains. Sodium stearate from Dalan Soap Factory was used in precipitation technique.

Precipitation Process. A $5.000 \mathrm{~g}(0.016 \mathrm{~mol})$ sample of sodium stearate, NaSt, was dissolved in $200 \mathrm{~mL}$ of deionized water in the reactor shown in Figure 1 at 70 ${ }^{\circ} \mathrm{C}$. A $2.345 \mathrm{~g}(0.008 \mathrm{~mol})$ portion of zinc sulfate heptahydrate was dissolved in $100 \mathrm{~mL}$ of deionized water at $30{ }^{\circ} \mathrm{C}$. After the sodium stearate was completely dissolved in water, the zinc sulfate solution was fed to the reactor by a peristaltic pump (Masterflex C/L) at a constant flow rate of $13.64 \mathrm{~mL} \cdot \mathrm{min}^{-1}$ The reaction temperature was maintained at $70{ }^{\circ} \mathrm{C}$ by a PID temperature controller (Love Controls Series2500). In this semi-batch process, the mixture was stirred at $500 \mathrm{rpm}$ with a four-bladed mechanical mixer. The reagents in eq 1 were used in equivalent amounts. The reaction was also carried out at $10 \%$ excess sodium stearate and $10 \%$ excess zinc sulfate. Since the byproduct $\left(\mathrm{Na}_{2} \mathrm{SO}_{4}\right)$ was soluble in water the reaction media was filtered by using a Büchner funnel under a $600-\mathrm{mmHg}$ vacuum. To remove the $\mathrm{Na}_{2} \mathrm{SO}_{4}$ completely, wet $\mathrm{ZnSt}_{2}$ was washed twice with $200 \mathrm{~mL}$ of deionized water. The wet $\mathrm{ZnSt}_{2}$ cake was dried in a vacuum oven at $400-\mathrm{mmHg}$ vacuum at $100{ }^{\circ} \mathrm{C}$. An experiment was also done by instantaneous mixing of equivalent amounts of reactants and taking aliquots of samples to study reaction kinetics at $70{ }^{\circ} \mathrm{C}$.

Fusion Process. A 113.78-g (0.40 mol) sample of stearic acid was molten at $70{ }^{\circ} \mathrm{C}$ above its melting point in the reactor and a $16.27 \mathrm{~g}(0.20 \mathrm{~mol})$ of zinc oxide $(\mathrm{ZnO})$ was added to the molten stearic acid. The reaction was carried out above the melting point of $\mathrm{ZnSt}$, at 140 ${ }^{\circ} \mathrm{C}$ and under atmospheric pressure. In this batch process, to determine the effect of stirring rate on reaction time, the mixture was stirred at 400,600 , and
$750 \mathrm{rpm}$ by a four-bladed mechanical mixer. Samples were taken from the reactor at different times to study the reaction kinetics.

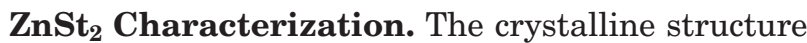
and purity of the $\mathrm{ZnSt}_{2}$ samples were determined by means of Philips Xpert-Pro X-ray powder diffractometer using $\mathrm{Cu} \mathrm{K} \alpha$ radiation at $45 \mathrm{kV}$ and $40 \mathrm{~mA}$. A scanning electron microscope, Philips XL30 SFEG, (SEM) with energy-dispersive X-ray (EDX) analyses was used for identification of particle size and product purity. The samples were coated with gold and palladium metals by using the sputtering technique. A Fourier transform infrared spectrophotometer (Shimadzu 8601) was used to determine functional groups of the products, the impurities in products, and reactant conversion by wellknown ratio method NaSt. $\mathrm{ZnSt}_{2}$ and stearic acid with different amounts in $\mathrm{KBr}$ were taken to determine the absorptivity of the compounds at 1560,1540 , and 1700 $\mathrm{cm}^{-1}$. Inductively coupled plasma atomic emission spectroscopy (ICP 96, Varian) was used to measure the zinc and sodium contents of $\mathrm{HNO}_{3}$ extracts of soaps. An elemental analyzer (CHNS-932 LECO) was used to determine the product constituents and the removal of byproduct, $\mathrm{Na}_{2} \mathrm{SO}_{4}$. Thermogravimetric analyses (Shimadzu, TGA-51) were utilized, in which $\mathrm{ZnSt}_{2}$ samples $(10-15 \mathrm{mg})$ were loaded into a $\mathrm{Pt}$ pan and heated from 30 to $1000{ }^{\circ} \mathrm{C}$ at $10{ }^{\circ} \mathrm{C} \mathrm{min}{ }^{-1}$ under $\mathrm{N}_{2}$ flow $\left(40 \mathrm{~cm}^{3}\right.$ $\min ^{-1}$ ). The melting behavior of each $\mathrm{ZnSt}_{2}$ sample was determined using transmission optical microscopy (Olympus, CH40) with a heated hot stage controlled by a temperature controller (Instec, STC 200C) and differential scanning calorimetry (DSC) (Shimadzu, DSC50). Melting of $\mathrm{ZnSt}_{2}$ particles was photographed by a digital camera (Nikon, Coolpix 995). DSC curves were taken by heating the samples at $10^{\circ} \mathrm{C} / \mathrm{min}$ rate up to $200{ }^{\circ} \mathrm{C}$ under $40 \mathrm{~cm}^{3} \mathrm{~min}^{-1}$ nitrogen gas flow.

\section{Results and Discussion}

Reaction Temperature. In the precipitation process, a reaction temperature of $70{ }^{\circ} \mathrm{C}$ was selected to have the NaSt solution concentration above $2.5 \%$ in water..$^{13}$ On the other hand, solubility of zinc sulfate is high enough at this temperature. In the fusion process, reaction temperature was selected as $140^{\circ} \mathrm{C}$, which was high above the melting point of the $\mathrm{ZnSt}_{2}$ to ensure low viscosity of the reaction medium.

Raw Material Characterization. EDX analysis of NaSt and zinc sulfate: Na 9.09\%, C 66.14\%, O 14.45\% (wt), and $\mathrm{Zn} 39.27 \%$, S $15.39 \%$, O $40.68 \%$ (wt) values were obtained. Carbon content of sodium soap (66.14\%) was lower than its theoretical value of $70.54 \%$, and sodium content $(9.90 \%)$ was greater than its theoretical value of $7.5 \%$. These results show that soap has a shorter alkyl chain length than stearate ion. Since EDX analysis was performed under ultrahigh vacuum, nearly $7 \mathrm{~mol}$ of hydrated water was removed from the zinc sulfate sample and $\mathrm{S}, \mathrm{O}, \mathrm{Zn}$ percent values were very close to that of anhydrous zinc sulfate.

Product Purity. EDX measurements have been done at three different points and average values of these results are reported in Table $1 . \mathrm{Zn}^{2+}$ ions were recovered from $\mathrm{ZnSt}_{2}$ samples using nitric acid for ICP analysis. The weight percents of $\mathrm{Na}^{+}$and $\mathrm{Zn}^{2+}$ ions were determined as shown in Table 1 . The product obtained for three different conditions in precipitation process according to eq 1 were very similar in composition. Elemental analysis results are lower than the theoreti- 
Table 1. Elements \% (w) for $\mathrm{ZnSt}_{2}$ Samples

\begin{tabular}{|c|c|c|c|c|c|c|c|c|c|c|}
\hline \multirow[b]{2}{*}{ elements } & \multirow[b]{2}{*}{ theor. } & \multicolumn{3}{|c|}{ equivalent } & \multicolumn{3}{|c|}{$10 \%$ excess $\mathrm{Zn}$} & \multicolumn{3}{|c|}{$10 \%$ deficient $\mathrm{Zn}$} \\
\hline & & ICP & EDX & $\overline{\mathrm{EA}^{a}}$ & $\mathrm{ICP}$ & EDX & $\overline{\mathrm{EA}^{a}}$ & ICP & EDX & $\overline{\mathrm{EA}^{a}}$ \\
\hline $\mathrm{C}$ & 68.43 & & 70.23 & 64.84 & & 68.15 & 63.96 & - & 68.54 & 65.72 \\
\hline $\mathrm{O}$ & 10.12 & & 7.14 & & & 8.75 & & & 9.06 & \\
\hline $\mathrm{Zn}$ & 10.34 & 13.53 & 12.17 & & 14.84 & 13.18 & & 12.33 & 10.52 & \\
\hline $\mathrm{Na}$ & & 0.1 & & & 0.02 & & & 0.521 & 1.04 & \\
\hline $\mathrm{H}$ & $11.09^{b}$ & & $11.09^{b}$ & 9.41 & & $11.09^{b}$ & 9.07 & & $11.09^{b}$ & 9.92 \\
\hline
\end{tabular}

${ }^{a}$ For elemental analysis (EA) results. ${ }^{b}$ For theoretical values of hydrogen.
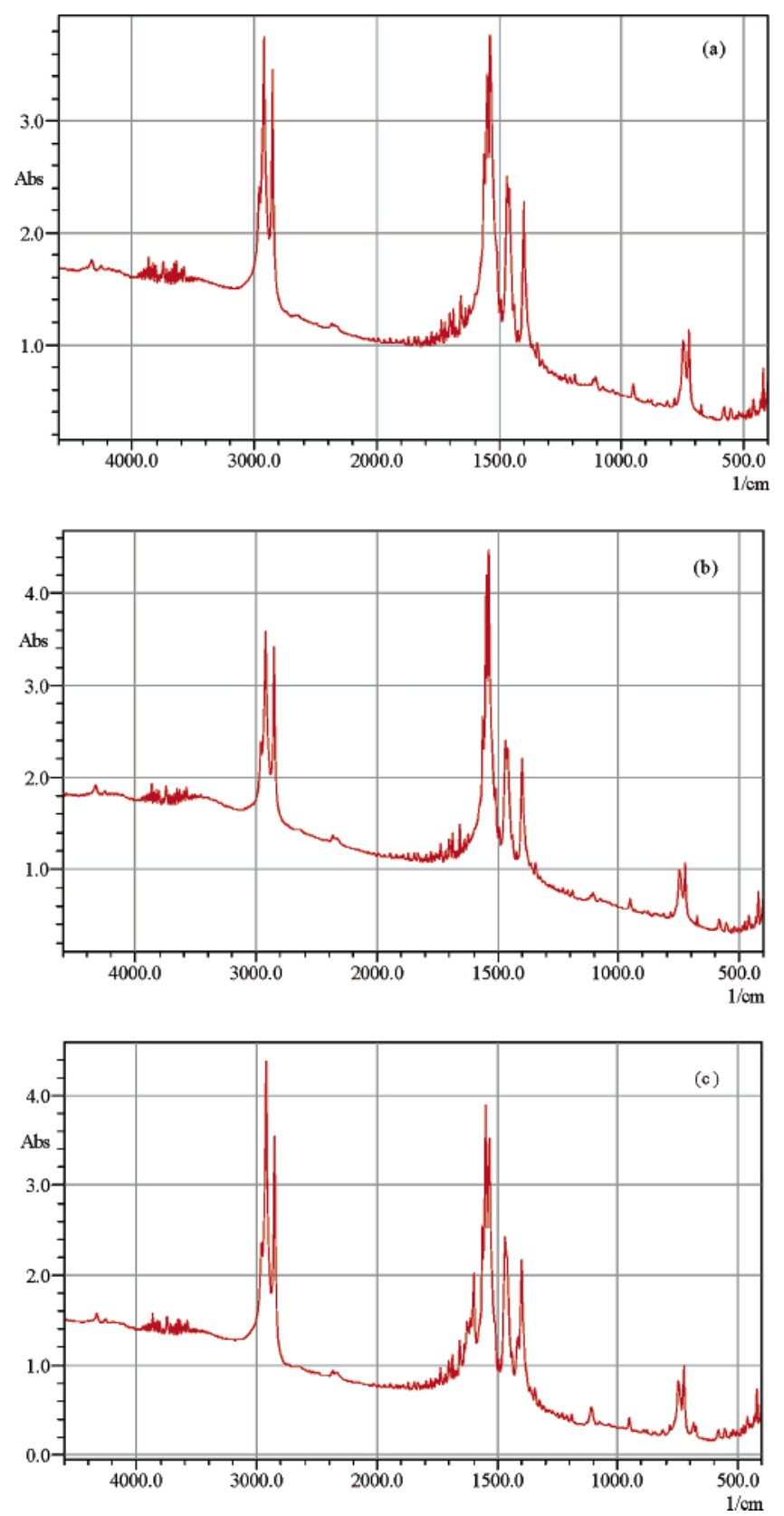

Figure 2. IR spectra of $\mathrm{ZnSt}_{2}$ for (a) equivalent, (b) excess, and (c) deficient $\mathrm{Zn}$ cases by precipitation process.

cal values. This result is assigned to low $\mathrm{C}$ content in the sodium stearate. This situation produced higher $\mathrm{Zn}$ content in the product. $\mathrm{Na}^{+}$ion concentration in product was higher $0.52 \%(\mathrm{w})$ for the deficient case than that of excess case $0.02 \%(\mathrm{w})$. The characteristic peaks of zinc stearate at 1540 and $1398 \mathrm{~cm}^{-1}$ were observed for the samples which were produced in precipitation process as shown in Figure $2 \mathrm{a}-\mathrm{c}$. These bands are due to antisymmetric and symmetric carboxylate stretching

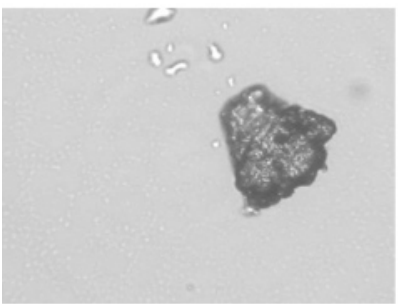

(a) at $122^{\circ} \mathrm{C}$

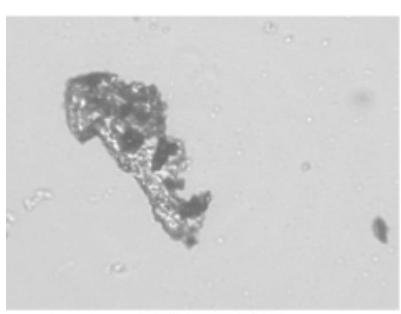

(c) at $120^{\circ} \mathrm{C}$

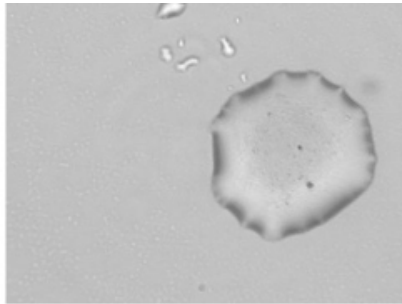

(b) at $123^{\circ} \mathrm{C}$

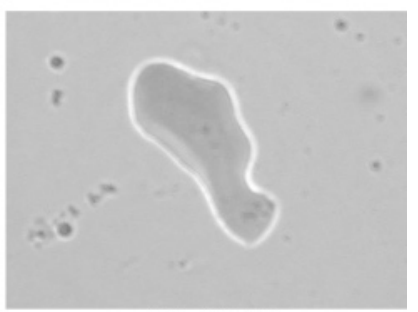

(d) at $122^{\circ} \mathrm{C}$
Figure 3. Transmission optical microscope photographs of equivalently $\mathrm{ZnSt}_{2}$ sample produced by precipitation process (a) at 122 ${ }^{\circ} \mathrm{C}$ and (b) at $123{ }^{\circ} \mathrm{C}$, and of $\mathrm{ZnSt}_{2}$ sample produced by fusion process at $750 \mathrm{rpm}$ sample (c) at $120^{\circ} \mathrm{C}$ and (d) at $122^{\circ} \mathrm{C}$.

bands $\left(v_{\mathrm{a}} \mathrm{COO}^{-}\right.$and $\left.v_{\mathrm{s}} \mathrm{COO}^{-}\right)$, respectively. ${ }^{2}$ Antisymmetric and symmetric methylene stretching, and methylene scissoring bands $\left(v_{\mathrm{a}} \mathrm{CH}_{2}, v_{\mathrm{s}} \mathrm{CH}_{2}\right.$, and $\left.\delta_{\mathrm{s}} \mathrm{CH}_{2}\right)$ were observed at about 2914, 2850, and $1472 \mathrm{~cm}^{-1}$, respectively. These bands are due to the alkyl chain in the zinc stearate structure. In Figure 2c, the band observed at $1560 \mathrm{~cm}^{-1}$ belongs to asymmetric stretching vibration $\left(v_{\mathrm{as}} \mathrm{COO}^{-}\right)$of the sodium soap. This shows the presence of unreacted sodium soap in the product. From the IR analysis it was found that raw materials must be fed in equivalent amounts in the production of zinc stearate by precipitation process. There are different reported values, such as $130{ }^{\circ} \mathrm{C}^{14}$ and $124-126^{\circ} \mathrm{C}^{15}$ for the melting point of $\mathrm{ZnSt}_{2}$. Phase transition temperatures of $\mathrm{ZnSt}_{2}$ samples from both precipitation and fusion processes were determined with the aid of the DSC analysis and optical examination. A sharp transition from opaque to transparent appearance between 120 and $123^{\circ} \mathrm{C}$ was observed by heating the sample on a hot stage microscope. The melting point of $\mathrm{ZnSt}_{2}$ produced by precipitation process was found to be 122 ${ }^{\circ} \mathrm{C}$ as shown in Figure $3 \mathrm{a}$ and $\mathrm{b}$. The fusion process product obtained according to eq 2 started to melt at $120^{\circ} \mathrm{C}$ and it was completely melted at $122^{\circ} \mathrm{C}$ as shown in Figure 3c and d. As it was pointed out by Akanni and Nbaneme, ${ }^{16} \mathrm{ZnSt}_{2}$ samples melt directly from the solid to the liquid phase. The presence of unreacted stearic acid in the fusion process product reduces the melting point of $\mathrm{ZnSt}_{2}$. In the present study, optical techniques and DSC gave similar melting points. The onset of melting was $120{ }^{\circ} \mathrm{C}$ and $118{ }^{\circ} \mathrm{C}$ and melting peak maxima were at $125.17{ }^{\circ} \mathrm{C}$ and $125.77^{\circ} \mathrm{C}$ for $\mathrm{ZnSt}_{2}$ by precipitation and fusion processes, respectively, as seen in their DSC curves in Figure 4, confirming the 


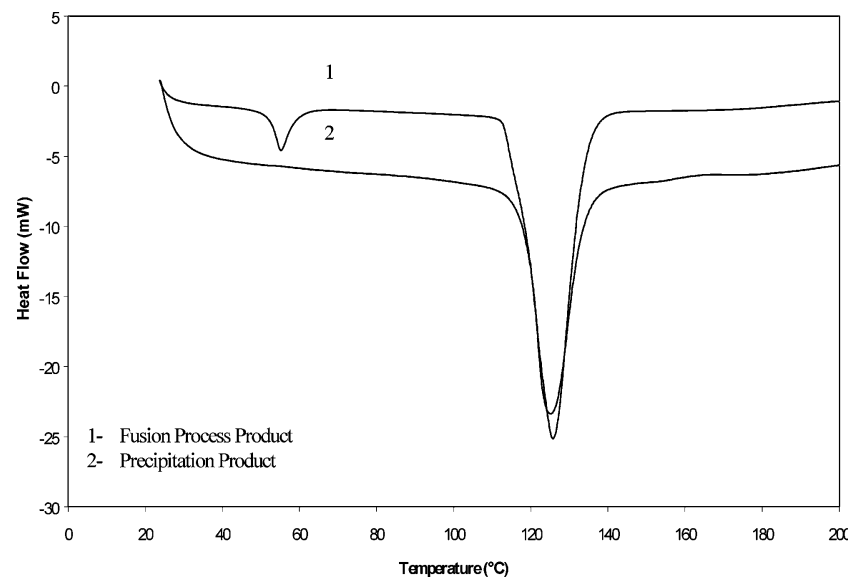

Figure 4. DSC curves of samples from precipitation and fusion processes.

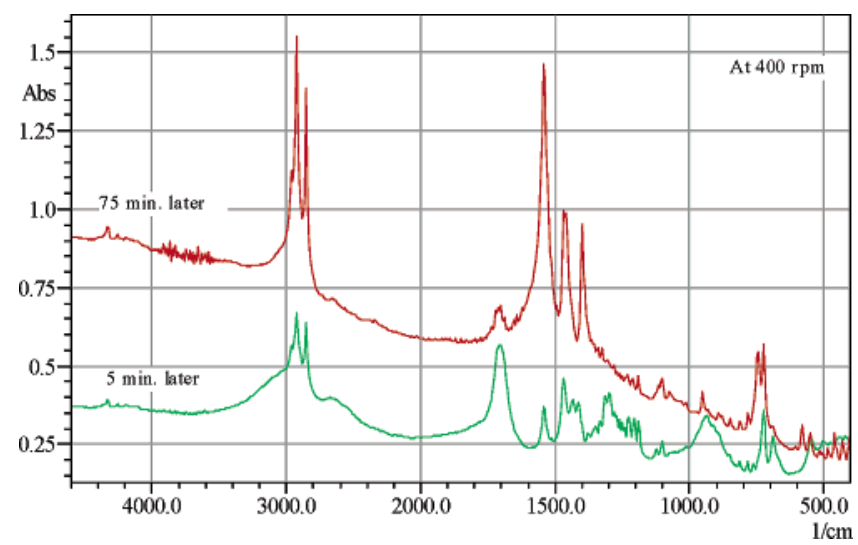

Figure 5. IR spectra of $\mathrm{ZnSt}_{2}$ at different times for $400 \mathrm{rpm}$ for the fusion process.

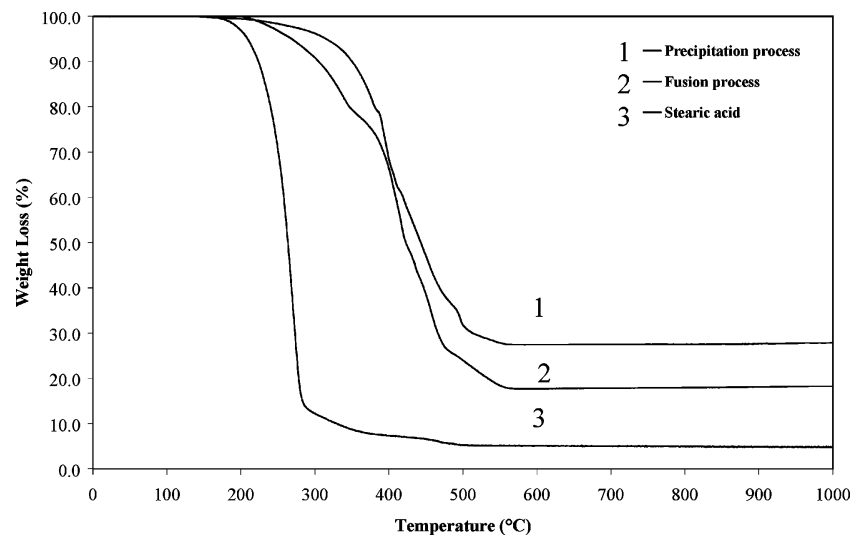

Figure 6. TGA curves of $\mathrm{ZnSt}_{2}$ samples from precipitation and fusion process.

optical solid-liquid-phase transition observed at about $120{ }^{\circ} \mathrm{C}$. ZnSt $\mathrm{Zn}_{2}$ from fusion process contained free stearic acid melting at $55.25{ }^{\circ} \mathrm{C}$ as shown in Figure 4 . The presence of palmitic acid (47.7\%) in the stearic acid used could be the reason for the melting points found in the present study to be lower than values reported in the literature. ${ }^{14,15}$ The presence of unreacted acid was verified by IR analysis by the presence of $\mathrm{C}=\mathrm{O}$ at 1700 $\mathrm{cm}^{-1}$ as seen in Figure 5 . The remaining mass of $\mathrm{ZnSt}_{2}$ samples at $1000{ }^{\circ} \mathrm{C}$ obtained from precipitation and fusion processes are $27.34 \%$ and $17.98 \%$, respectively as seen in Figure 6. $\mathrm{ZnSt}_{2}$ from precipitation process began to lose weight at $100^{\circ} \mathrm{C}$. On the other hand, $\mathrm{ZnSt}_{2}$ from fusion process started to lose weight at $270{ }^{\circ} \mathrm{C}$ at

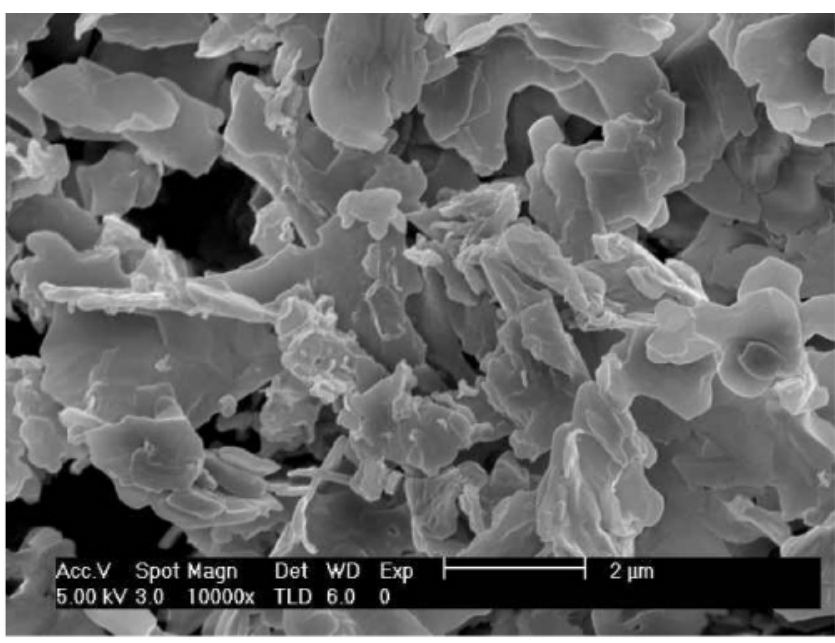

(a)

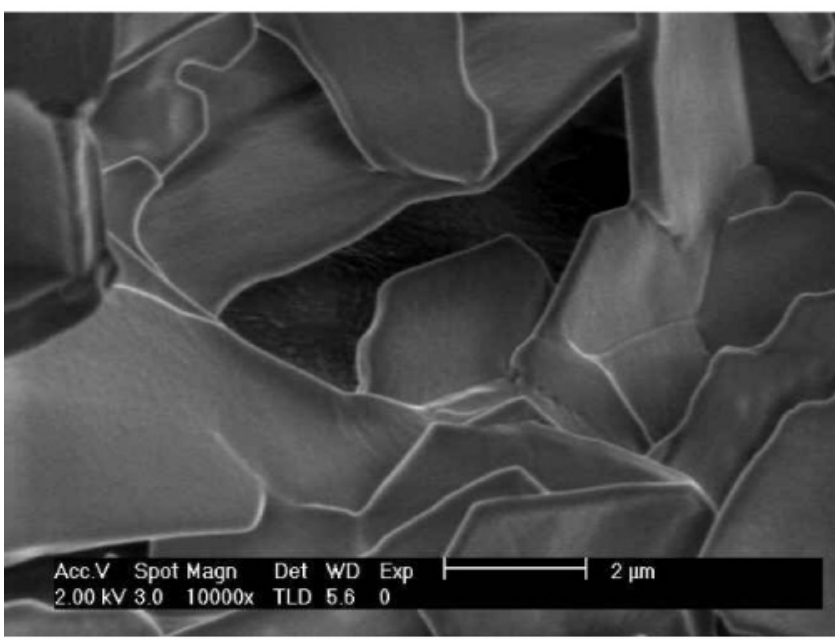

(b)

Figure 7. SEM micrograph of $\mathrm{ZnSt}_{2}$ samples produced by (a) precipitation process and (b) fusion process.

which degradation starts. Total loss for fusion process product occurred as $82.01 \%(\mathrm{w})$, and above $550{ }^{\circ} \mathrm{C}$ no loss was observed. The precipitation product lost $72.64 \%$ of its initial weight, and above $550{ }^{\circ} \mathrm{C}$ no weight loss was observed. The remaining compound at the end of thermal treatment could be oxide and carbonate of zinc metal. ${ }^{1}$ Although the analysis of decomposition products was not performed, it was thought that major decomposition products of $\mathrm{ZnSt}_{2}$ were carbon dioxide, alkanes, and ketones as gas products. ${ }^{17}$ As pointed out by Jaw et al., ${ }^{18}$ stearic acid decomposed giving $5 \%$ in weight carbonaceous residue as seen in Figure 6. Since $\mathrm{ZnSt}_{2}$ from the fusion process contained unreacted stearic acid, it had a lower remaining mass in TGA analysis.

Morphology of Particles. Figure 7a shows the crystal morphology of $\mathrm{ZnSt}_{2}$ sample produced in the equivalent case of the precipitation process. It has a random platelike crystal. The particle size of samples changed between 2 and $4 \mu \mathrm{m}$. It can be seen from Figure $7 \mathrm{~b}$ that the fusion process particle size of $\mathrm{ZnSt}_{2}$ samples changes between 4 and $6 \mu \mathrm{m}$. Since $\mathrm{ZnSt}_{2}$ had crystallized from melt in the fusion process, the crystal shapes of particles in fusion process were different from the $\mathrm{ZnSt}_{2}$ particles obtained by the precipitation process. The particles had sharper edges and were more orderly packed than the ones from precipitation process. 


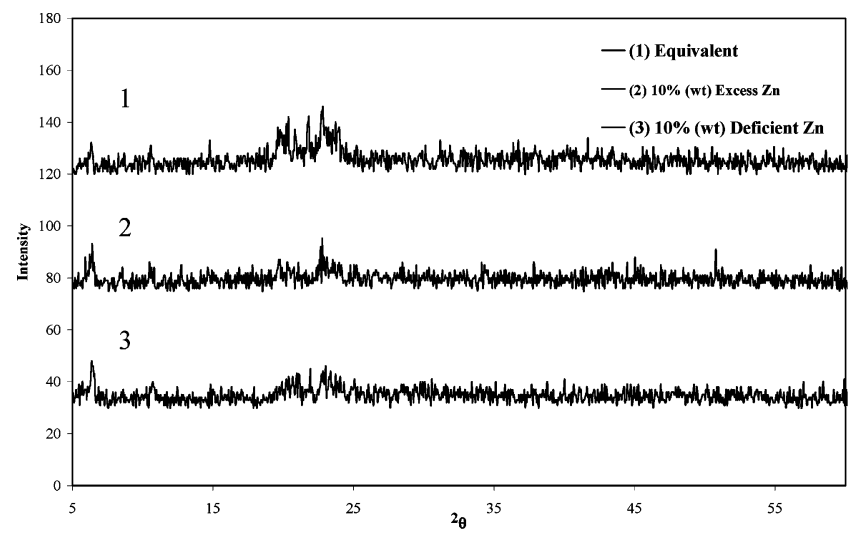

(a)

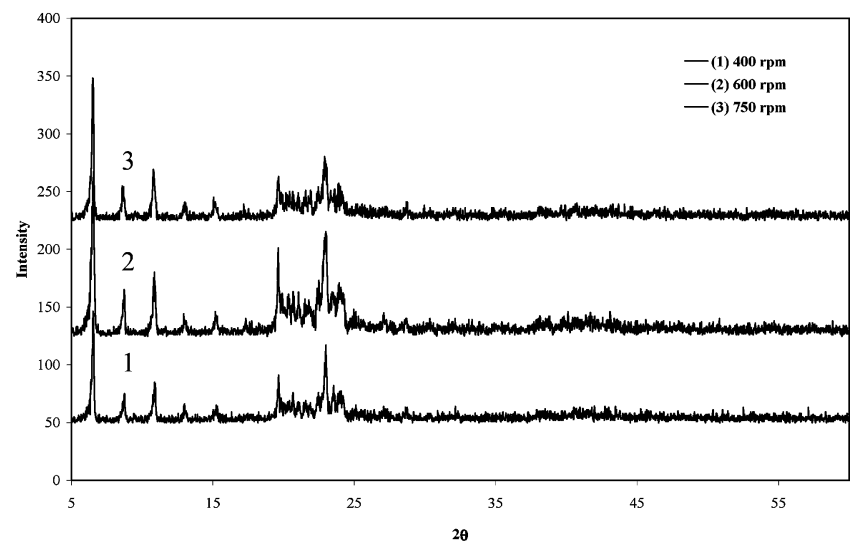

(b)

Figure 8. XRD pattern of $\mathrm{ZnSt}_{2}$ samples produced by (a) precipitation process and (b) fusion process, at different mixing rates.

Crystal Structure. Although all of the XRD patterns are noisy, two of the characteristic $2 \theta$ values of zinc stearate at $6.40^{\circ}$ and $19.58^{\circ}$ were observed in Figure $8 \mathrm{a}$ for $\mathrm{ZnSt}_{2}$ prepared by the precipitation process. The noise of the patterns is caused by the amorphous structure of zinc stearate. The reason for this amorphous structure might be the reaction phase in which the product cannot be packed in an orderly fashion. On the other hand, the presence of micelles in the reaction phase might have some diminishing effects on crystallinity of the product. ${ }^{14}$ Figure $8 \mathrm{~b}$ shows that $\mathrm{ZnSt}_{2}$ samples produced by the fusion process have their own characteristic peaks at $2 \theta$ values of $6.55^{\circ}, 8.77^{\circ}, 10.93^{\circ}$, $19.67^{\circ}$, and $22.99^{\circ}$, except the $2 \theta$ at $37.93^{\circ}$. These results are consistent with literature values. ${ }^{19}$

Zinc Coordination with Carboxylate Ions. The elemental analysis by EDX reported in Table 1 indicates $7.14 \% \mathrm{O}$ and $12.17 \% \mathrm{Zn}$ for the precipitation process. This corresponds to $2.4 \mathrm{~mol}$ of $\mathrm{O}$ atoms per $\mathrm{Zn}$ (II) ion in contrast to the theoretical value of $4 \mathrm{O}$ atoms per mol of $\mathrm{Zn}$ in the $\mathrm{ZnSt}_{2}$ molecule. The coordination of oxygen atom to $\mathrm{Zn}$ is in chelating form since only the IR peak at $1540 \mathrm{~cm}^{-1}$ was present in the IR spectra of ZnSt,'s presented in Figure 2a, b, and c of this study. If they were in ionic form a peak at $1576 \mathrm{~cm}^{-1}$ would be seen. ${ }^{20}$

Kinetic Studies. The characteristic bands, functional groups, and specific absorptivity values determined from IR spectra of samples having different concentrations and using Beers' law, are shown in Table 2. As can be seen in the Figure 5 with elapsing time of reaction, the

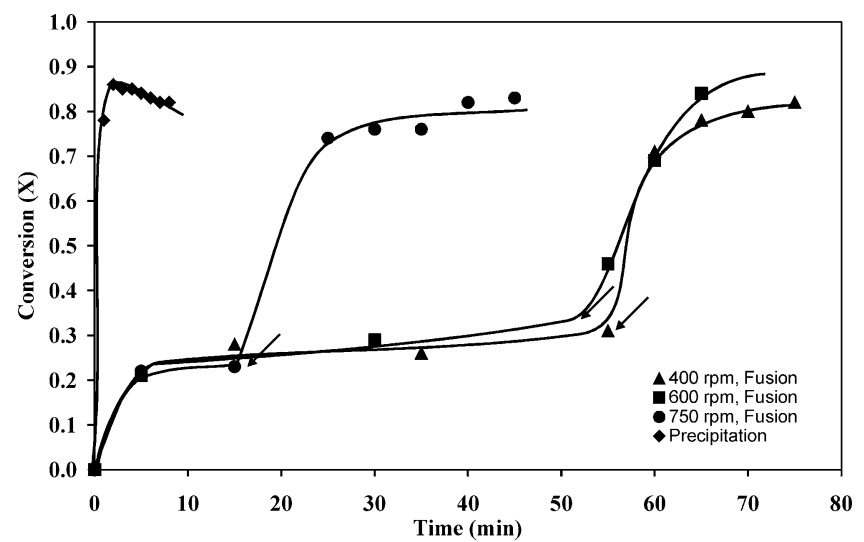

Figure 9. Change of conversion with elapsing time for different mixing rates (arrows indicate start of the second step in the reaction).

Table 2. Characteristic Vibration, Wavenumber of the Band, and Absorptivity of Functional Groups of Compounds

\begin{tabular}{llcc}
\hline compound & vibration type & $\begin{array}{c}\text { wavenumber } \\
\left(\mathrm{cm}^{-1}\right)\end{array}$ & $\begin{array}{c}\text { absorptivity }(\epsilon) \\
200 \mathrm{mg} \mathrm{KBr} / \mathrm{mg}\end{array}$ \\
\hline $\mathrm{NaSt}$ & $\mathrm{COO}^{-}$stretching & 1560 & 4.55 \\
$\mathrm{ZnSt}{ }_{2}$ & $\mathrm{COO}^{-}$stretching & 1540 & 3.48 \\
stearic acid & $\mathrm{C}=\mathrm{O}^{\text {stretching }}$ & 1700 & 1.20
\end{tabular}

characteristic peak of stearic acid at $1700 \mathrm{~cm}^{-1}$ due to $\mathrm{C}=\mathrm{O}$ stretching vibration decreased and the characteristic band of zinc stearate at $1540 \mathrm{~cm}^{-1}$ due to $\mathrm{COO}^{-}$ stretching vibration increased for the fusion reaction. However, after a certain time, no change was observed in the height of the stearic acid band which showed unreacted stearic acid remained in the product. The conversion obtained was $20 \%$ at the beginning of the reaction, and its rate increased suddenly after an induction period and reached a limiting value around $80 \%$ in a very short time. For 400,600 , and $750 \mathrm{rpm}$ stirring rates the induction times were 54,52 , and 15 min, respectively, as seen in Figure 9. This period was attributed to the barrier film of zinc stearate formed on the surface of the zinc oxide particles. Replacement of this film with fresh stearic acid was more rapid at high stirring rates, decreasing the induction period of the reaction. The reaction was completed in a time period less than $1 \mathrm{~h}$ in this study; a shorter period than the $3-4 \mathrm{~h}$ reported previously by other workers. ${ }^{6}$

The change of conversion with elapsing time is shown in Figure 9 for both processes. The ratio of absorbance of NaSt's $\mathrm{COO}^{-}$groups' vibration at $1560 \mathrm{~cm}^{-1}$ to absorbance of $\mathrm{COO}^{1-}$ groups' vibration of $\mathrm{ZnSt}_{2}$ at 1540 $\mathrm{cm}^{-1}$ was obtained from the IR spectra of every sample taken during the precipitation reaction. By using this ratio, conversion was calculated according to eq 4 . The same procedure was used in the fusion process using the ratio of absorbance of $\mathrm{C}=\mathrm{O}$ groups of stearic acid at $1700 \mathrm{~cm}^{-1}$ to absorbance to $\mathrm{COO}^{-}$groups vibrations of $\mathrm{ZnSt}_{2}$.

$$
X=\frac{2 \epsilon_{1}}{\epsilon_{2} \frac{A_{1}}{A_{2}}+2 \epsilon_{1}}
$$

where $\epsilon_{1}$ is the absorptivity of reactant (NaSt or stearic acid), $\epsilon_{2}$ is the absorptivity of product $\left(\mathrm{ZnSt}_{2}\right)$ in $\mathrm{mg} /$ $200 \mathrm{mg} \mathrm{KBr}$, and $A_{1}$ and $A_{2}$ are absorbance values of reactant and product, respectively. 
The fast ionic reaction between NaSt and $\mathrm{ZnSO}_{4}$ occurred within a few minutes and the conversion reached a value of about $86 \%$ with respect to NaSt as shown in Figure 9. It was assumed that only sodium stearate and $\mathrm{ZnSt}_{2}$ were present in small samples taken in the precipitation process. The reaction may occur in two consecutive steps: first with the substitution of $0.5 \mathrm{~mol} \mathrm{Zn}$ (II) ions with $1 \mathrm{~mol} \mathrm{Na}$ ions with the formation of $\mathrm{NaZn}_{0.5} \mathrm{St}_{2}$, then further substitution to give $\mathrm{ZnSt}_{2}$. Existence of the probable intermediate product $\mathrm{NaZn}_{0.5} \mathrm{St}_{2}$ was totally neglected in conversion calculations since no IR spectroscopic data for $\mathrm{NaZn}_{0.5} \mathrm{St}$ were present. Free acid formation by hydrolysis of sodium stearate in water was also negligible, since no carbonyl group peak of stearic acid at $1700 \mathrm{~cm}^{-1}$ was present in the IR spectrum of $\mathrm{ZnSt}_{2}$ obtained by the precipitation process. Thus, the decrease of conversion with time from 0.86 to 0.82 in 8 min shown in Figure 9 could be attributed to error introduced in conversion calculations by the presence of intermediate products.

In the fusion process the reaction seemed to occur in two steps; the reaction took place between the solid zinc oxide particles and molten stearic acid in the first step. The synthesized zinc stearate formed a shell at the surface of the zinc oxide and hindered the diffusion of the stearic acid onto the zinc oxide surface. With elapsing time, the shell of zinc stearate was removed by mechanical mixing from the zinc oxide surface and the fast second step begins. In the second step, the highest conversion reached was $82 \%$ with respect to stearic acid. Since the carbon chain length of the stearic acid was lower than $\mathrm{C} 18$, higher $\mathrm{COOH}$ functional groups per mole of the acid used in this study were present. The stearic acid contained 52.3\% C18 and 47.7\% C16 alkyl chain and the acid number was 208.2 $\mathrm{mg} \mathrm{KOH} / \mathrm{g}$. Excess acid functional groups $(6 \%)$ were present in the fusion process reaction mixture as calculated using the acid number $(208.2 \mathrm{mg} \mathrm{KOH} / \mathrm{g})$ of stearic acid and molar mass of the mixture of stearic (53.3\%) and palmitic acids (47.7\%) at the present study. Even if $\mathrm{ZnO}$ should be the limiting reagent in this case, less conversion (82\%) was obtained than expected (97.5\%) indicating there should be other reasons such as reversibility of reaction and mass transfer limitations which should be further investigated.

\section{Conclusions}

The fusion process was slower than the precipitation process. At least 45 min was required for $80 \%$ conversion. This time period was much shorter than the reported reaction time for other metal soaps. ${ }^{6}$ For the precipitation process, the following conclusions were drawn: The solubility of the sodium stearate determines the important parameters, e.g., amount of water required, reaction temperature, etc., in this process. NaSt at $2.5 \%(\mathrm{w})$ is an optimum solubility value at $70{ }^{\circ} \mathrm{C}$ for the reaction. However, this low solubility of NaSt caused an increase in the amount of water used in the reaction. Therefore, further washing and filtration processes were required. The other anticipated result is the treatment of wastewater effluent from process. It was concluded from XRD patterns that zinc stearate was not orderly packed and crystallinity was low. SEM micrographs showed that zinc stearate crystal morphology was in lamellar form. The particle size was found to be between 2 and $4 \mu \mathrm{m}$. From their IR spectra, it was seen that highly pure zinc stearate was obtained from the pre- cipitation process with an equivalent raw materials ratio when compared to the fusion process.

For the fusion process the following conclusions were drawn: The shortest reaction time of $45 \mathrm{~min}$ was obtained at a $750 \mathrm{rpm}$ stirring rate and $140{ }^{\circ} \mathrm{C}$ for the same conversion value of $80 \%$. Vigorous agitation increased the collision of the reactants. Although the reaction temperature was two times greater than that of the precipitation process, synthesized zinc stearate samples contained unreacted raw material; the presence of unreacted stearic acid in the product was observed in both its IR spectrum and DSC curve. $\mathrm{ZnO}$ was the limiting reagent since stearic acid used has a shorter chain length than C18. XRD patterns showed that zinc stearate crystallinity was greater than the precipitation process product crystallinity. Since the product was obtained from melt, it was more orderly packed. From SEM micrographs, zinc stearate crystal structure was observed as layered lamellar form. The particle size of zinc stearate was found to be between 4 and $6 \mu \mathrm{m}$ from SEM micrographs. The phase change of the zinc stearate samples was observed as from solid to liquid directly for both processes. In the precipitation process the melting point of samples was found to be $122^{\circ} \mathrm{C}$. The melting points of samples from fusion process were found to be slightly lower than $122{ }^{\circ} \mathrm{C}$ due to the presence of stearic acid.

Using excess $\mathrm{ZnSO}_{4}$ and $\mathrm{ZnO}$ in the precipitation and fusion processes would ensure the higher conversion of NaSt and stearic acid, respectively. The risk of having free $\mathrm{ZnSO}_{4}$ could be eliminated by washing the product in the precipitation process. On the other hand it would be preferable to have excess $\mathrm{ZnO}$ than free stearic acid in $\mathrm{ZnSt}_{2}$ produced by the fusion process. Using a turbomixer could be preferred to eliminate mass transfer limitations in the fusion process. Using commercial stearic acid containing palmitic acid lowered the melting points of $\mathrm{ZnSt}_{2}$ produced by both the precipitation and fusion processes, but this would not effect the functions of $\mathrm{ZnSt}_{2}$ obtained as heat stabilizers and lubricants.

\section{Acknowledgment}

We acknowledge financial support from The Scientific and Technical Research Council of Turkey (TÜBİTAK) and Izmir Institute of Technology Research Fund for projects MISAG-185 and 2001MÜHYL-05, respectively.

\section{Literature Cited}

(1) Akanni, M. S.; Okoh, E. K.; Burrows, H. D.; Ellis, H. A. The thermal behavior of divalent and higher valent metal soaps-a review. Thermochim. Acta 1992, 208, 1-41.

(2) Sakai, H.; Umemura, J. Evaluation of molecular structure in Langmuir monolayers of zinc stearate and zinc 12-hydroxystearate by IR external reflection spectroscopy. Colloid Polym. Sci.e 2002, 280, 316-321.

(3) Simons, M. J. U.S. Patent 3,839,049, 1974

(4) Yoshizawa, F.; Kikuchi, F.; Kojima, S.; Yuasa, K. U.S. Patent 5,175,322, 1992.

(5) Poulenat, G.; Sentenac, S.; Mouloungui, Z. Double Decomposition Reactions for the Production of Alkaline and AlkalineEarth Oleic Soaps under Salting-Out Conditions. Ind. Eng. Chem. Res. 2004, 43, 1574-1579.

(6) Blachford, J. U.S. Patent 4,316,852, 1982.

(7) Kato, Y. U.S. Patent 6,162,836, 2000.

(8) Hudson, J. R.; Nelson, E. N. U.S. Patent 5.164.523, 1992.

(9) Margues, E. F.; Burrows, H. D.; Miguel, M. G. The structure and thermal behaviour of some long chain cerium(III) carboxylates. J. Chem. Soc., Faraday Trans. 1998, 94 (12), 1729-1736. 
(10) Abrahamson, H. B.; Lukaski, H. C. Synthesis and characterization of iron stearate compounds. J. Inorg. Biochem. 1994 $54,115$.

(11) Ishioka, T.; Maeda, K.; Watanabe, I.; Kawauchi, S.; Harada, M. Infrared and XAFS study on structure and transition behavior of zinc stearate. Spectrochim. Acta, Part A 2000, 56, 1736

(12) Gökçel, H. I.; Balköse, D.; Köktürk, U. Effects of mixed metal stearates on thermal stability of rigid PVC. Eur. Polym. J. $\mathbf{1 9 9 9}, 35,1507$.

(13) Mul, M. N. G.; Davis, H. T.; Evans, D. F.; Bhave, A. V.; Wagner, J. R. Solution-phase behavior and solid-phase structure of long-chain sodium soap mixtures. Langmuir 2000, 16, 82768284 .

(14) Weast, R. C.; Astle, M. J. Handbook of Chemistry \& Physics; CRC Press: Boca Raton, FL, 1980.

(15) Ekwunife, M. E.; Nwachukwu, M. U.; Rinehart, F. P.; Sime, S. J. Properties of molten carboxylates. J. Chem. Soc., Faraday Trans. I 1975, 71, 1432.

(16) Akanni, M. S.; Nbaneme, P. C. The molten phase conductance and the thermotropic phase transition in lead(II), zinc(II) and cadmium(II)10-hydroxyoctadecanoates. Thermochim. Acta 2003, 401,200 .
(17) Artok, L.; Schobert, H. H. Reaction of carboxylic acids under coal liquefaction conditions. 1. Under nitrogen atmosphere. J. Anal. Appl. Pyrolysis 2000, 54, 215-233.

(18) Jaw, K. S. Hsu, C. K. Lee, J. S. The thermal decomposition behaviour of stearic acid, paraffin wax and polyvinyl butyral. Thermochim. Acta 2001, 367-368, 167.

(19) Jona, E.; Pajtasova, M.; Ondrusova, D.; Simon, P. Influence of temperature on curative interactions with participation of metal carboxylate as adhesive promotors: the interactions $\mathrm{Cu}$ (II) hexadecanoate with stearic acid, $N, N^{\prime}$-dicyclohexylbenzothiazole-2sulfenamide, sulfur and zinc oxide. J. Anal. Appl. Pyrolysis 2002, 63,25 .

(20) Benavides, R.; Edge, M.; Allen, N. S. The mode of action of metal stearate stabilisers in poly(vinyl chloride). I. Influence of preheating on melt complexation. Polym. Degrad. Stab. 1994, 44, $375-378$.

Received for review July 9, 2004

Revised manuscript received December 1, 2004

Accepted December 17, 2004

IE0493980 